\title{
THE POLICY OR FUNCTION OF THE LAW OF BILLS AND NOTES
}

\author{
John S. Strahorn, Jr. $\dagger$
}

The law of bills and notes applies to the transactions in which commercial paper is involved a group of rules peculiarly different from the normal rules of procedural, property, and contract law which otherwise would govern them. What is there about bills of exchange, bank checks, and promissory notes which justifies their being constituted a corps d'elite of the law? What policy, what end, what function is sought to be served by applying to bills and notes transactions rules of law appreciably different from the normal rules which govern business activity in general?

The general policy of the law of bills and notes is to encourage the conducting of money or credit transactions in a commercially desirable manner by holding out to transactions so conducted the reward of a preferred status under the law. This general policy subsumes two subsidiary policies concerned, respectively, with form and substance which, with their correlative legal peculiarities and operative facts, furnish the basis for the classification here to be followed.

The first policy involves the form of money or credit transactions. This policy is to encourage the shaping of such transactions into forms which commercial desirability dictates. The policy is served by holding out the reward of the procedural advantages which accrue to the ordinary holder of a negotiable instrument if the transaction be shaped into one of the molds approved by commercial practice. These advantages will follow regardless of the internal honesty of the transaction.

The second policy involves the substance of money or credit transactions. Its aim is to encourage the conducting of the formal type transactions on a basis of the utmost honesty and commercial desirability, and is served by holding out the reward of the substantive advantages which accrue to the holder in due course of a negotiable instrument. For these to follow there must be, in addition to the approved formal conduct, the approved substantial conduct.

Thus the corps d'elite of the law of bills and notes has two levels of merit with ascending strata of advantages granted to the obligee in

† A. B., I922, St. John's College; LL. B., I925, Washington and Iee University; S. J.D., I926, Harvard University; J. S. D., I93I, Yale University ; Professor of Law at University of Maryland School of Law; author of The Effect of Impossibility on Criminal Attempts (1930) 78 U. of PA. L. REv. 962; Criminology and the Law of Guilt (1936) 84 U. OF PA. L. REv. 49I, 600; A Reconsideration of the Hearsay Rule and Adnissions (I937) 85 U. OF PA. L. REv. 484,564, and other articles in legal periodicals. 
order to encourage both the shaping and the conduct of money or credit transactions in a commercially desirable manner.

The first policy, of encouraging the shaping of all money or credit transactions into approved forms, regardless of their internal honesty, proceeds on the premise that social and economic welfare will be fostered if such transactions be carried on in the form of negotiable bills, notes, and checks, rather than by less formal means. It is believed that the resulting greater use of these approved types of commercial instruments will, by providing substitutes for money and facile instruments of credit, ${ }^{1}$ make the most efficient use of the available supply of money and credit and so increase the volume of business done in the marketing of the world's goods and the use of human services.

The second policy is more concerned with the internal honesty of the transaction which is carried on by means of the approved form of commercial instrument. Its aim is to encourage the more commercially desirable conduct of the good faith and innocent investment of money or other value in future obligations. Of course, the prospect of substantive advantages will also encourage people to shape ordinary transactions into the approved forms.

Implicit in both these policies is the idea not only of encouraging the occurrence of transactions which might not happen at all save for the bait of the advantages held out, but also of causing those transactions which probably would occur in an informal manner to be conducted both as to form and substance in the commercially desirable manner.

The common purpose of the rules of law giving effect to these policies is to detract from the position of the debtor or owner and to grant extraordinary privileges to the creditor, lender, or investor. ${ }^{2}$ At first sight this would indicate that the rules might defeat their own purposes by discouraging the borrowing or debtor class from using these peculiar types of transaction. But the creditor class is economically superior. It is able both to dictate to the debtor class the form which the transactions shall take and to perform the acts making for the more commercially desirable holding in due course. Thus the grant of jural favors to the creditor group does stimulate the greater use of these type transactions and the more frequent occurrence of intrinsic honesty in the manner of their circulation.

I. For a discussion of whether negotiable instruments serve as substitutes for money or instruments of credit, see Waterman, The Promissory Note as a Substitute for Money (I930) I4 MINN. L. REv. 313.

2. There are at least two minor attributes of the law of bills and notes giving the debtor a superior position if the transaction be a negotiable, rather than a non-negotiable one. The obligor is safer in making payment of a negotiable instrument, as he has the sure proof of that fact by the taking up of the instrument. The anomalous indorser is in a happier position on a negotiable instrument, for then he is entitled to steps of diligence, whereas on a non-negotiable one he would be a co-maker and absolutely liable. 
In discussing the subject in detail the writer will attempt to use terminology and classifications which will describe the subject matter in terms of the "commercial policy" approach herein adopted. There will be no attempt to solve or discuss minutely all the numerous unsolved and debatable problems of the law which result either from the lacunae and other imperfections of the Statute or from judicial disagreement thereunder. Certain of these problems will be used, however, because of their utility in catalyzing functional discussions under various headings and, to the extent that considerations of commercial policy may suggest the proper solutions, these latter will be presented. Beyond that nothing more will be done than to recognize that unsettled problems exist.

The detailed topics will be: I. The procedural advantages rewarding the ordinary holder; II. The substantive advantages rewarding the holder in due course; III. The minimum commercial conduct creating the procedural advantages; IV. The more desirable commercial conduct creating the substantive advantages; and, V. The commercial conduct terminating the advantages.

\section{The Procedural Advantages Rewarding the Ordinary HOLDER}

The tenor of these procedural advantages is to facilitate the holder's enforcement of the liability incidental to the instrument and to make it more difficult for the respective obligors to escape liability and for other persons to claim ownership of the instrument. As to ordinary holders all of the common-law requisites of contract or transfer of chose in action are necessary in order that there be created liability to or ownership in the holder. ${ }^{3}$ The absence of any fundamental requirement of a common-law contract or transfer, or the presence of some legal obstacle thereto, would as certainly prevent liability or title from arising here as it would in a common-law transaction. But the reward for shaping the transaction into the form approved by the law of bills and notes is the benefit of a group of peculiar rules. The effect of these rules, is to minimize the difficulty of proving the presence of the necessary, and the absence of the objectionable features set up by the law of contracts and property. ${ }^{4}$

These procedural advantages fall into five groups: (A) The minimizing of the difficulty of transfer; (B) The minimizing of the

3. NEGotiabLe INSTRUMENTS LAw, $\S 58$. In the ensuing footnotes the various sections of the Uniform Negotiable Instruments Law will be referred to merely by section number.

4. Section 5 provides that the negotiability of an instrument shall not be affected by an express stipulation for certain privileges advantageous to the obligee in enforcing the transaction. 
pleading difficulties; (C) The minimizing of the operative facts for liability and ownership; (D) The minimizing of the evidential requirements to prove the operative facts; and, (E) The minimizing of the evidential requirements to establish the more desirable status of the holder in due course.

\section{A. The Minimizing of the Difficulty of Transfer}

Negotiability or free transferability is by far the outstanding achievement of the peculiar law of bills and notes. The concept of the capacity of the original and subsequent obligees to transfer their rights to the fullest extent to anyone whom they may choose not only stands at the apex of the procedural advantages themselves but forms the foundation of the higher group of substantive advantages (immunity from personal defenses and claims of ownership, and capacity to transfer such quality) which are extended to the more worthy holders in due course.

Where the common law gave the contractual obligee few enough privileges and would not permit him to transfer any of those, the law of bills and notes gives to the original obligee far more privileges in his own right, allows him to transfer all of them to another ordinary holder, and gives any one the power of creating still greater privileges in the hands of a holder in due course by making transfer to such a person. ${ }^{5}$

The concept of "negotiability" or of the instrument's being a "negotiable instrument" thus has three aspects, in only the last two of which is the question of transfer involved. One and the same set of operative facts, later to be treated, determines whether the instrument is a "negotiable instrument", from the standpoint of: (I) whether the original obligee may enforce the obligation with the aid of the peculiar procedural advantages of the ordinary holder; (2) whether the instrument is capable of being properly transferred to another ordinary holder who may, himself, enforce it with the aid of these procedural advantages; ${ }^{6}$ and, (3) whether it is capable (if the requisite further operative facts occur) of being transferred to a holder in due course who will receive the additional substantive advantages accruing to such an exalted person. "Negotiability" includes all of these ideas." Thus the

5. $\$ \S 57,58$.

6. On this, consider $\$$ I (4) (instrument must be payable to order or bearer); $\$ \S 8,9$ (when so payable); $\$ 34$ (difference between special and blank indorsements).

7. See Smith, The Concept of "Negotiability" as Used in Section 47 of the Negotiable Instruments Law (I929) 7 TEx. L. REv. 520, dealing with the various senses of "negotiable" and particularly with the question of the extent to which a restrictive indorsement terminates negotiability. Consider also the narrower sense of "negotiation" under $\$ 30$, and the difference between a holder by negotiation and one owning under $\$ 49$. 
happening of maturity will cut off "negotiability" in the third sense, but not in the first two. ${ }^{8}$

This quality of transferability, which arises from the same operative facts which make it possible for the original obligee to enforce the instrument by the procedural advantages, makes it possible for the proper transferee to have the complete legal title, i. e., complete capacity likewise to enforce the instrument through the assistance of all the procedural advantages accruing to the original ordinary holder. This was not so by the common law of contracts and procedure. By this law the obligee could not even transfer the lesser privileges which accrued to him. Either the concept of privity between the original parties to the contract, or the fear of increased litigation if one person were allowed to enforce a promise made to another was the basis of the common-law rule that obligations were not assignable. While the common law itself, aided by sporadic statutes, has modified this rule, particularly by the device of the equitable assignment and the suit in the name of the assignor on behalf of the assignee, the law of bills and notes has long gone farther and has recognized that desirable commercial practice demands that negotiable instruments should be freely transferable. It thus permits the law merchant assignee to enjoy to the fullest all the rights and privileges of the assignor. ${ }^{9}$

Not only are the rewards accorded the transferee for having taken transfer to be considered privileges given him, but the possibility of making transfer, or further transfer, must be considered as an inducement to the original and subsequent holders to become such and to deal in negotiable paper.

The concept of transfer underlies one of the two forms of negotiable instrument. The bill of exchange itself involves an apparent or attempted transfer by the drawer of the drawee's indicated obligation to him. Implicit in the drawing of the bill is the drawer's indication either that he believes the drawee already to be obligated to him or that he expects the drawee to make advances on his behalf. While, for reasons of policy later to be discussed, the law does not attach to the drawing of the bill the consequences of an assignment even on the common-law level, yet, nevertheless, the drawing of it does simulate an assignment to the payee or bearer of the expected performance by the drawee.

8. Consider the last sentence of $\S 7$ which provides that overdue paper shall be treated as demand paper with reference to persons becoming obligated on it after maturity.

9. Consider that one of the results of transferability, even as to an ordinary holder, is the transferee's freedom from a claim of set-off of an obligation between the obligor and the transferor. To this extent there is a substantive difference between the ordinary holder and the common-law assignee. 


\section{B. The Minimizing of the Pleading Difficulties}

The next point wherein the law of bills and notes differs markedly from the common law-and that in favor of the obligee-is in the minimizing of the difficulties of pleading incidental to the enforcement of the obligations involved in the transaction. The first instance of this, connected with the minimizing of the difficulty of transfer, lies in the capacity of the holder other than the original payee to sue upon the transaction in his own name. ${ }^{10}$

Not only may a transferee-holder sue in his own name, but every holder, either the original payee or a proper transferee, is empowered to bring the suit in his own name not merely upon the transaction underlying the instrument but (with less difficulty) upon the instrument itself considered as the contract, viz., as a mercantile specialty analogous to a sealed instrument. In pleading, the underlying transaction is replaced by the instrument, which, for this purpose, is deemed to represent the obligation.

This is something more than the privilege of drafting a briefer declaration, of alleging the execution of the instrument rather than the making of a promise, with all the subjective details possibly involved therein. There is dispensed with the need of alleging the presence of the requisite elements of contractual liability which the normal law of procedure would require for a common law contract. There are said to be four elements of a contract, legal subject matter, competent parties, consideration, and mutual assent, which last in the case of a written contract, is evidenced by delivery. The first two are, by the normal law of procedure, defensive in nature, and need not be alleged in the plaintiff's declaration. The holder of a negotiable instrument need make no further allegations of the latter two elements of consideration and delivery than by alleging that the defendant executed the instrument.

Further, when the plaintiff suing is a remote holder, his pleading difficulty is minimized (as contrasted with the situation obtaining under the modified common law) by the ease with which he may allege (and later prove) the transfer or transfers by which the instrument reached him. Under the procedural advantages accruing to an ordinary holder, all that needs to be done is to allege the indorsement by such persons as, according to the tenor of the instrument, are necessary indorsers. Should the paper have been originally bearer paper, it is sufficient to allege its issuance, without mentioning the possibly numerous intervening assignments which might have happened. If the instrument started 225.

I0. $\S 5$ I. The problems raised by $\$ \S 37$ and 49 are discussed infra, notes 223,224 , 
as order paper and later by blank endorsement became and remained bearer paper, it is necessary only to allege indorsements as far as the first blank indorsement, after which the pleader may ignore later actual transfers. Did the paper pass by simple assignment, it would be necessary to allege in detail each contract of assignment, which is a much more onerous task. ${ }^{11}$

Tied up with the above advantages is the concept of a negotiable instrument as not one, but several contracts, one for each of such separate transactions as making, drawing, accepting, or indorsing. One and the same piece of paper, by virtue of being signed at different times and on different parts thereof, may become different contracts, enforced by different lawsuits. Thus not only does a holder sue on the instrument, but he sues the defendant in a particular capacity on the instrument, and it may be important in a given case to determine what is the capacity of the instant defendant on the particular instrument which he may have signed.

To settle this question of what is the capacity in which a particular signer of a given instrument should be sued, the Statute offers further procedural advantages in numerous provisions for clearing up ambiguities raising doubts as to the proper form of pleading. Thus if it is doubtful whether the instrument is a bill or a note, the holder may choose which to consider it. ${ }^{12}$ It is also provided that a signature not otherwise explained shall be regarded as that of an indorser, and thus a person so signing may be sued in that capacity. ${ }^{13}$ Definite provision is made to determine to whom an irregular indorser shall be liable. ${ }^{14}$ Indorsers are prima facie liable to one another in the order in which they indorse. ${ }^{15}$ Joint indorsers are considered as jointly and severally liable, ${ }^{16}$ as are signers who place two or more signatures to an instrument reading "I promise to pay." 17

\section{The Minimizing of the Operative Facts for Liability and Owenership}

The most fundamental aspect of this minimizing of essential operative facts is seen in the rule that liability on and transfer of a proper negotiable instrument may be accomplished by nothing more (and sometimes less) than the conduct of the obligor's or transferor's signing his name on the instrument and intentionally delivering it to the
II. Ibid.
12. $\$ \S I 7(5), 130$.
I3. $\$ \S I 7(6), 63,67$.
I4. $\S 64$.
I5. $\S 68$.
I6. Ibid.
I7. $\S$ I7 (7). 
object of his dealing. ${ }^{18}$ Thus, the contracts of the drawer, ${ }^{19}$ maker, ${ }^{20}$ acceptor, ${ }^{21}$ and indorser, ${ }^{22}$ all follow by legal implication from the fact of signing one's name in the appropriate position on the instrument, and later delivering it. It is not necessary to express the words of the obligation, further than by the "promise or order" in the body of the instrument. ${ }^{23}$ The maker and the acceptor, by the bare signature, accomplish as much as if they should write out in full: "I promise to pay this sum at the specified date." The drawer and the indorser, likewise, accomplish as much as if they should say: "I promise to pay upon the following conditions." From the transfer aspect, the act of the holder in indorsing order paper accomplishes as much as if he had written out a complete contract of transfer.

Then, under appropriate conditions, as we shall see, liability and transfer may be accomplished even in the absence of signature, from the bare fact of the delivery of the instrument, or from other recognized conduct. Thus a drawee may be held to have constructively accepted a bill addressed to him by virtue of his commercial misconduct with reference to the bill, even where he has not signed his name with intention to accept. ${ }^{24}$ Then, too, one who transfers an instrument without indorsement, or even where he does indorse, in addition to his normal indorser's liability, acquires the liability of a warrantor from the bare fact of transfer. ${ }^{25}$ And, it is quite possible to make an effectual transfer by mere delivery, even without signature, and without expression of the contract of assignment. If the paper be, at the time, bearer paper, the transfer by bare delivery accomplishes a full negotiation and creates all the procedural advantages in the transferee, ${ }^{26}$ and if it be at the time order paper, a transfer without indorsement creates practically equivalent procedural advantages in the transferee. ${ }^{27}$

Even in situations where the signature is considered essential, occasional exceptional rules permit it to be made in abnormal manner. Examples are the indorsement on a separate paper attached to the instrument, ${ }^{28}$ the analogous acceptance on a separate writing, ${ }^{29}$ and the valid

18. Consult $\$ 31$ (how indorsement made); $\$ 67$ (indorsement of bearer paper). Section 16 recognizes the requirement of delivery. See also $\$ 23$ (forgery).

I9. $\$ 6 \mathrm{I}$. The drawer may, however, insert a provision negativing or limiting his liability to the holder. Ibid.

20. $\$ 60$.

2I. $\$ 62$.

22. $\$ \S 66,67$.

23. $\S$ Io (any terms sufficient if they indicate an intention to conform to the Statute); § I4 (blanks).

24. $\$ \$ 136,137$.

$25 . \S \$ 65,66,69$.

26. $\$ 330,34,40$.

27. $\$ 49$.

28. \$3r.

29. \$§ I34, 135 . 
acceptance of a bill which is incomplete in many respects. ${ }^{30}$ One may sign through an agent ${ }^{31}$ and, as a further minimizing of the operative facts, the Statute makes it clear that the appointment of the agent may be established informally. ${ }^{32}$ If one signs actually as agent but without disclosing his principal, he is penalized for this commercially undesirable conduct by being subjected to liability himself which he could have avoided had he indicated both his agency and the identity of his principal. ${ }^{33}$

The extraordinary quality of the law of bills and notes for working liability with greater facility in favor even of the ordinary holder is further seen when we consider the nature of the liability of the drawer, indorser, and transferor. That of the maker and the acceptor is, of course, analogous to that of an ordinary common-law promisor and the law merchant does no more than to work it with unusual ease. But on the drawer, indorser, and transferor a liability is imposed which is more extensive than at common law. ${ }^{34}$ The law merchant adds to the warranty liability of the common law the conditional secondary liability which is imposed on certain of these parties automatically by virtue of their assuming such capacities.

Another aspect of the minimizing of otherwise essential operative facts in favor of ordinary holders consists of the admissions which the Statute sets up as incidental to the acts of assuming the various types of liability. Thus the maker, ${ }^{35}$ drawer, ${ }^{36}$ and acceptor ${ }^{37}$ "admit" the existence of the payee and his then capacity to indorse, and the indorser and transferor ${ }^{38}$ not only make this admission but actually may incur liability for its non-existence by their warranties that all prior parties had capacity to contract. The acceptor also makes certain admissions as to the drawer. ${ }^{39}$ Thus in suing any of these parties it is not necessary to allege or prove the existence and contractual capacity of the payee or of any parties prior to an indorser or transferor. Hence certain of the operative facts otherwise essential to complete transfer

30. 138 .

3I. § I9.

32. Ibid.

33. $\$ 20$. Consider also $\$ 42$ concerning paper addressed to one as "Cashier" or other fiscal officer, and $\$ 69$ concerning the warranty liability of an agent or broker who negotiates by delivery without disclosing his principal.

34. The indorser and transferor would, of course, be common-law assignors and subject to the warranty liability thereof. The closest analogy for the drawer under the common law would be to an assignor and, as was pointed out earlier in the text, the drawing of a bill does simulate an assignment although the law refuses to treat it as such for reasons of commercial policy. \$\& 127, I89. The drawee is not liable unless and until he accepts.
35. $\$ 60$.
36. $\$ 6 \mathrm{r}$.
37. $\$ 62(2)$.
38. $\$ \$ 65,66$.
39. $\$ 62(I)$. 
are dispensed with to the greater advantage of the ordinary holder. So it is that the indorsement or assignment by a corporation or an infant passes the property even though the indorser or assignor did not have contractual capacity. ${ }^{40}$

While consideration is as much requisite in the case of an ordinary holder as in that of the common-law obligee, ${ }^{41}$ yet certain provisions of the Statute purport to clarify the requirement so as to avoid any doubt. "Thus, an antecedent debt is "value",42 and one who holds by way of lien holds for value. ${ }^{43}$ It is made clear that an accommodation party may be liable even to one aware of the fact of accommodation. ${ }^{44}$ But any statute requiring the nature of the consideration to be stated remains in force. ${ }^{45}$

Finally, an instrument need not be dated, ${ }^{46}$ nor need it specify the value or any value, ${ }^{47}$ nor the place where drawn or payable; ${ }^{48}$ and postdating or ante-dating is permitted. ${ }^{49}$ The leniency as to blank spaces in an instrument, and the various rules for settling ambiguities, have been referred to, and will be again.

\section{The Minimizing of the Evidential Requirements to Prove the Operative Facts}

Various rules minimize the difficulty of proving those operative facts which still are requisite as to ordinary holders. Typical rules of this sort are the presumptions which make out a prima facie case of the existence of the requisite operative facts from other and more easily proven evidential facts. Thus, while consideration is required as to an ordinary holder, the Statute presumes it for the issuance of the instrument and for the signing by every party, ${ }^{50}$ Further, the necessary valid

40. \$22. Consider, however, the judicial limitation of this doctrine with respect to the infant's assertion of a claim of ownership of the proceeds of the instrument. Consider also $\$ 42$ on the question of transferring corporation paper.

4 I. $\S 28$.

42. $\$ 25$.

43. $\$ 27$.

44. $\$ 29$.

45. $\$ 6$.

46. $\$ 6(\mathrm{I})$.

47. $\$ 6(2)$. Consider $\S 26$ which declares that where value has at any time been given, the holder hoids for value as to all parties becoming liable prior to the value being given.

48. $\$ 6(3)$.

49. § I2.

50. $\$ 24$. Consider also $\$ 6(4)$ which declares that negotiability shall not be affected by the presence of a seal, and the question which has arisen thereunder: whether (for an actually sealed instrument) the rebuttable presumption of consideration under the statute or the common-law rule dispensing entirely with it shall prevail as to an ordinary holder. 
delivery of the instrument by a person whose signature is on it is presumed from the fact of the instrument's being out of his possession. ${ }^{51}$

Two other procedural advantages of this sort are not found in the Statute but are found in the case law and extrinsic legislation of many states. One lies in the provisions to the effect that the defendant's failure to deny, by pleading, the validity of a well pleaded signature shall be taken as a judicial admission of the genuineness of the signature. Under these provisions it is often possible for an ordinary holder to recover merely by filing the instrument and resting his case. Normally, and under the uniform statute, proof of necessary signatures must be made in order that the holder prevail. The other of these advantages not found in the Statute is embodied in the rule permitting the use of the notary's certificate of protest to prove the essential operative facts of presentment and notice in order to bind secondary parties. This rule makes it possible to dispense with the calling of human witnesses to prove these happenings. Protest is required in order to bind secondary parties on foreign bills, and is made permissible in order to facilitate this essential proof in the case of inland bills and all notes. ${ }^{52}$

A miscellaneous group of presumptions provided for by the Statute also aid the ordinary holder in making out his case. ${ }^{53}$ For purposes of the rule of protest, a bill is presumed to be and may be treated as an inland bill ${ }^{54}$ unless the contrary is apparent. A date on an instrument or any act thereon is presumed to be the correct date thereof..$^{55}$ Every indorsement is presumed to have been made at the place where the instrument itself is dated. ${ }^{56}$ Indorsers are liable prima facie in the order in which they indorse. ${ }^{57}$ Various rules ${ }^{58}$ purport to clear up ambiguities in the transaction by means of presumptions, including the rule ${ }^{59}$ presuming an unexplained signer to be an indorser. It is presumed that an instrument payable to one as a named fiscal officer of a bank or corporation is payable to such institution. ${ }^{60}$

5I. $\S \mathrm{x}$. This must be considered, of course, in the light of $\$ 15$. The rule resultant from the two Sections is that the total lack of delivery of an incomplete instrument is an absolute defense, available even against a holder in due course.

52. Consider $\$ \$ 152$ to 160 , inclusive, treating of the details of protest.

53. But $c f . \S \mathrm{I} 23$ which presumes an apparent cancellation to have been intentional and authorized.

54. $\S \S I 29$, I 52.

55. $\$ I I$. Contrast $\S 12$ (title passes at time of actual delivery of a post-dated or ante-dated instrument); $\S 136$ (acceptance dates as of day of presentment); $\$ 17(2)$ (interest presumed to run from date of instrument or time of issue if undated); $\S$ I7 (3) (where not dated, instrument considered to be dated as of time of issue).

56. $\S 46$.

57. $\S 68$.

58. $\$ 17$. indorser.

59. $\$ \$ 17(6), 63$. Consider also $\$ 64$ delimiting the liability of the irregular

$60 . \$ 42$. 
E. The Minimizing of the Evidential Requirements to Establish the More Desirable Status of the Holder in Due Course

A decided advantage given the ordinary holder by the law is the presumption that he is a holder in due course, viz., that he took for value, in good faith, without notice, and before maturity, thus obtaining the consequent substantive advantages. Thus every holder is deemed prima facie a holder in due course, but the burden may be shifted to him to prove that he is such when the defendant or claimant makes preliminary proof of defective title in him as defined by the Statute, viz., when there exists a defense or claim involving "crookedness." 61 In the latter event there is more danger that the alleged holder is a catspaw for a thief or fraud-feasor and so it is thought better to make the holder prove that he does hold in due course, or that a predecessor did.

\section{The Substantive Advantages Rewarding the Holder in Dú COURSE}

Where the procedural advantages rewarding the ordinary holder merely facilitate his recovery on the instrument under the usual requirements of the elements of contractual liability and transfer, the substantive advantages reward the more commendable holder in due course by dispensing entirely with some of the requirements of contractual liability, or by removing completely some of the normal obstacles to such recovery or to the retention of the instrument. Thus the peculiarities of the law are here substantive in nature rather than procedural.

These substantive advantages ${ }^{62}$ which reward the more commendable holder in due course are primarily of two sorts, first, an immunity from certain personal defenses which otherwise the obligor could assert to defeat liability, and, second, an immunity from certain claims by other persons to ownership of the instrument or its proceeds. A third form of substantive advantage is the capacity of the holder in due course to transfer his substantive advantages to another who is only an ordinary holder or assignee.

The former two, which are the principal capacities constituting the more privileged status of the holder in due course, are merely specific examples in the law of bills and notes of a concept found sporadically in many branches of the law, viz., the protection of the bona fide pur-

6I. $\$ 55$. Consider also whether, when the burden has shifted under this Section, the holder has the benefit of the presumption of value under $\$ 24$, and of indorsement before maturity under $\$ 45$.

62. Section $\mathbf{5 7}$ sets up the immunity from defenses specifically and, along with $\S 58$, is the statutory source of the whole calendar of substantive advantages. Contrast the use of the phrase "in due course" in $\$ 88$ with reference to payment, and, in a similar connection, in $\$ 5$ I. 
chaser under circumstances when a balancing of the equities indicates that the change of position of the bona fide purchaser makes it less desirable that he bear the loss which must be borne by someone than that it be borne by the one whose conduct has made the loss possible.

\section{A. Immunity from Personal Defenses to Liability}

While the maker of a note, for instance, may normally defend against the payee for any reason the common law permits ${ }^{63}$ (save that the procedural advantages make it relatively more difficult to do so) he will be liable to one who has taken, in the first instance or later, as a holder in due course despite a defense, so long as the defense is personal. ${ }^{64}$ A few of the typical common law defenses to liability may be asserted even against a holder in due course, and so it is that an investigation of the substantive advantages of the holder in due course calls for a demarcation of the personal defenses or equities on the one hand from the real or absolute defenses on the other. The latter may be asserted even against a holder in due course.

The personal defenses or equities are those which the law regards as so insignificant that, with respect to them, it is more equitable to make the obligor take the risk of the instrument's getting to a holder in due course than it is to make the holder in due course take the risk of their existence. On the other hand, the real or absolute defenses are those so important that with respect to them it is more fair to make the investor take the risk of their existence than it is to make the obligor take the risk of a holding in due course. As to the real or absolute defenses, either the policy of the law against enforcing liability is so strong or the intention of the obligor to acquire liability is so slight (if any there be) that the injury to the obligor if he be forced to pay is considered to outweigh the damage to the investor in being denied the fruits of his investment.

The solution of what defenses are "available to prior parties among themselves," ${ }^{65}$ i. e., what are personal defenses or equities, as distinguished from the real or absolute defenses, is a matter of specific statutory mandate in some instances and of judicial construction in the others.

Thus the Statute squarely provides that among the real or absolute defenses which may be asserted even against one otherwise a holder in due course there shall be included the forgery of the obligor's signature, $^{66}$ any variation by way of material alteration from the original

63. $\S 58$.

64. $\$ 57$.

65. Ibid.

66. §23. 
tenor of the instrument, ${ }^{67}$ and the total lack of delivery of an incomplete instrument. ${ }^{68}$ On the other hand, judicial interpretation both before and after the Statute has added to the calendar of real or absolute defenses those of fraud in the esse contractus; (possibly) physical duress; actual but not indicated running of the Statute of Limitations; lack of contractual capacity; ${ }^{69}$ and "statutory invalidity". ${ }^{70}$

There must be excluded from the category of real or absolute defenses certain topics which apparently are, but actually are not, real or absolute defenses. These are all properly listed as events "terminating the advantages", i. e., discharging liability on the instrument. All such events provide at most only personal defenses to liability although, as it happens, some of them are of such a nature as to make it impossible to have a subsequent holding in due course. In cases of the latter type these events have the mere appearance of real defenses. Examples of these latter are the intentional physical destruction or mutilation of the instrument, or discharge by payment at or after maturity. Both of these "terminate the advantages" and, along with other acts accomplishing that end, furnish the personal defense of that name, although these particular ones, as it happens, are of such a nature as to preclude a subsequent holding in due course. To the extent to which a subsequent holding in due course is legally possible, the discharge or avoidance of the instrument by the conduct terminating the advantages furnishes at most only a personal defense from which the subsequent holder in due course is immune.

Thus the insertion of the wrong date in the date blank, which would avoid the instrument as to an ordinary holder and terminate his right to enforce it by the procedural advantages, does not affect the holder in due course who may rely on the accuracy of the dating of the instrument. ${ }^{71}$ So it is with the failure to give notice of dishonor by non-acceptance of an instrument not necessary to be presented for acceptance. Failure of notice discharges secondary parties, i. e., terminates the procedural advantages against them, but if the instrument should come to a holder in due course who is ignorant of the presentment and dishonor, he may enforce their secondary liability regardless of their being discharged as to ordinary holders. ${ }^{72}$ On the other hand the problem cannot arise for discharge of secondary parties by failure to notify of dishonor by a non-acceptance upon a necessary pre-

67. $\$ \S 124,125$.

68. $\$ 15,16$.

69. Consider the problems raised by $\$ 22$, referred to herein, supra note 40 .

70. Incidentally applicable on this point is $\$ 6$-end (no repeal of statutes requiring nature of consideration to be stated); and $\$ 5$-end (nothing to validate any provision otherwise illegal).

7r. $\$ 13$.

72. § II7. 
sentment at a definite date, because the lack of entry of the acceptance would put the alleged holder in due course on notice of the failure. ${ }^{73}$ So it is with discharge of secondary parties by failure to take proper steps at maturity. That the instrument was taken subsequently would negative a holding in due course as to obligations accrued before maturity.

The prior termination of the advantages as against any party by the proper renunciation by a prior holder is, likewise, but a personal defense not to be asserted against a holder in due course ignorant thereof. ${ }^{74}$ So it is with the whole calendar of material alterations of the instrument 75 which avoid the entire instrument as to ordinary holders, thus terminating the procedural advantages, but which, so far as a holding in due course is subsequently possible, do not affect due course holders. They may enforce the instrument according to its original tenor. But to the extent of the variation from the original tenor, an absolute defense exists.

Then, turning to the personal defenses in general, the Statute provides that the holder in due course may enforce an instrument according to its appearance even though actually blanks have been filled in in a manner not authorized by the obligor sought to be held. ${ }^{78}$ As to an ordinary holder the obligor can defend on the ground that blanks have been improperly filled in, or have been properly filled in, but after a reasonable time has elapsed.

The two principal areas clearly established as only personal defenses by the Statute itself are those of consideration and delivery, which by themselves comprehend two of the four essential elements of contractual liability. Where as a matter of the procedural advantages of ordinary holders these elements are but rebuttably presumed, as to holders in due course they are entirely dispensed with. The defense of lack or failure of consideration cannot be set up against a holder in due course. ${ }^{77}$ Further, one who has put his signature to a complete instrument cannot defend against a holder in due course on the ground that he never intentionally delivered the instrument, nor can one who has signed an incomplete instrument and delivered it to another for any purpose defend on the ground that such other abused his authority in completing the instrument and negotiating it. ${ }^{78}$ As we have seen, total lack of delivery of an incomplete instrument is a real defense.

73. Of course, this would not be so for paper payable " 30 days after sight" because on that there would be nothing to indicate, from the mere lack of an acceptance, that there had been a presentment and a refusal.

74. § I22.

75. $\$ 124,125$.

$76 . \S 14$

$77 . \S 28$.

78. $\S \S 5,16$. 
The Statute itself calls for judicial interpretation of the remaining personal defenses by its provision ${ }^{79}$ that the holder in due course, in addition to holding free from defenses available to prior parties among themselves, also holds free "from any defect of title of prior parties." While this seems to comprehend claims of ownership as well, yet, when interpreted in the light of a previous Section ${ }^{80}$ defining "defective title", it indicates the statutory intention to have listed under the personal defenses the facts of the obtaining of the instrument by "fraud, duress, or force and fear, or other unlawful means, or for an illegal consideration, or when . . . [negotiated] . . . in breach of faith, or under such circumstances as amount to a fraud". ${ }^{81}$ This "general welfare" clause, also used in the Statute as the test for determining the burden of proof on the issue of holding in due course, purports to enable one to determine whether a given defense is personal or real, i. e., whether the holder in due course is immune from it or not. The ultimate limits of the personal defenses are defined in another Section of the Statute providing that in the hands of a holder other than one in due course (unless he claims under such a holder in due course) the instrument is subject to the same defenses as if it were not negotiable. ${ }^{82}$

\section{B. Immunity from Claims of Orenership of the Instrument}

The next aspect of the substantive advantages accruing to the holder in due course is the immunity from the claims of others to ownership of the instrument. The holder in due course may retain the instrument or its proceeds in situations where the ordinary holder would have to surrender it or them to the rightful owner of the instrument from whom it had passed without his full consent and intention. Again the attitude of placing the loss on the one who by his conduct made it possible is seen, here with reference to depriving one of ownership.

Thus the former owner of an instrument which was already bearer paper, or which became such by his blank indorsement, or which he indorsed specially to one who actually secured and properly negotiated it, takes the risk of being unable to recover it or its proceeds from a holder in due course who has taken it from or under a finder, thief, dishonest agent or other fraudulent negotiator, or from an apparent transferee where the consideration for the transfer has failed.

79. $\$ 57$.

80. $\$ 55$.

8I. Ibid.

82. $\S 58$. Consider the apparent intention of $\S 66$ of the Statute to confer only on holders in due course the benefit of the warranty liability of the unqualified indorser. There is no limitation in $\S 65$ which creates the warranties of the qualified indorser and the transferor by delivery. 
But the former owners take these risks only where the instrument contains valid signatures of all parties whose signatures are essential for transfer. Holders in due course take the risk of the forgery of a necessary signature. ${ }^{83}$ To this extent, forgery might be analogized to one of the "absolute defenses" discussed under the previous heading of immunity from personal defenses. But a better explanation is that when a necessary signature is forged, the possessor of the instrument is not even an ordinary holder and so cannot hold in due course.

The principal aspects of this immunity from claims of ownership arise usually in connection with delivery and sometimes in connection with consideration. While, even as to an ordinary holder, an intentional transfer of an already valid instrument of another may be made by way of gift, without any consideration (by intentional delivery of the instrument itself), yet when the transfer is made upon a consideration which fails there arises in the transferor a claim to the ownership of the instrument which he may assert against ordinary holders but not against holders in due course. ${ }^{84}$ Failure of contemplated consideration presents a claim of ownership.

Thus it would be with the failure of an expressed condition in an indorsement. ${ }^{85}$ Holders subsequent to the conditional indorsee take with notice of the condition and in the event of its non-occurrence may have to surrender the instrument or its proceeds to the conditional indorser.

An oral condition incidental to an indorsement, made valid by the Statute ${ }^{86}$ as to ordinary holders, and valid at common law as to the same class despite the parol evidence rule (if a condition precedent). will not avail as to a holder in due course who was unaware of it.

The unavailability of this particular claim of ownership is but one of the aspects of the application of the general rule that lack of intentional delivery of the instrument may not be asserted as a claim of ownership against a holder in due course, ${ }^{87}$ where it could be asserted against an ordinary holder. The two recognized ways of accomplishing transfer under the Statute are by delivery of bearer paper and indorsement and delivery of order paper. In the absence of delivery there is no law merchant transfer and hence a claim of ownership. But even as to ordinary holders there is a rebuttable presumption of delivery by any person whose signature appears on the instrument. As to

83. $\$ 23$. Consider also the problem of infancy under $\$ 22$, supra note 40 , and whether a transfer for a gambling debt may be set aside after the instrument has reached a holder in due course.

84. $\$ 28$.

85. $\$ 39$.

86. § I6.

87. § I6; $c f . \S I 5$. 
holders in due course delivery is conclusively presumed, i. e., dispensed with. Whether the claim be that the owner claiming never delivered at all, or delivered on an unperformed condition, or to a person for a limited purpose which was exceeded, the holder in due course is equally immune. ${ }^{88}$

The Statute expresses the concept of immunity from claims of ownership by the rule that the holder in due course holds free from any defect of title of prior parties. ${ }^{89}$ This defect is declared to exist where the signature or the instrument itself has been obtained by fraud, duress, force and fear, other unlawful means, or for an illegal consideration, or where the instrument has been negotiated in breach of faith or under circumstances which amount to a fraud. ${ }^{90}$ The subjection of the ordinary holder to all claims of ownership is nowhere expressly set out in the Statute, but it follows from the express rule ${ }^{91}$ that the holder in due course is free from such claims, and from the analogous rule ${ }^{22}$ that the ordinary holder is subject to the same defenses as if the instrument were non-negotiable.

\section{Capacity to Transfer the Substantive Advantages to an Ordinary Holder or Assignee}

The third and least important of the substantive advantages which reward the commercially commendable conduct of holding in due course is the power of the holder in due course to transfer the substantive advantages to one who, because he may have taken after maturity, or without giving value, or in bad faith, or with notice, is himself only an ordinary holder (or, even worse, a common law assignee)..$^{93}$ This power is expressed conversely by the rule that an ordinary holder "stands in the shoes" of a holder in due course if he "derives his title through" such a person. ${ }^{\text {94 }}$

An exception to the rule is made, however, in the case of one who was himself an earlier ordinary holder or a party to the irregularity, thus posing the question of holding in due course vel non. There would be too much danger of a simulated holding in due course to serve the

88. The distinction of $\S \S 55,16$, between complete and incomplete instruments would seem immaterial with respect to claims of ownership, as distinguished from defenses to liability, because, in the former instance the instrument would either have been complete to begin with or been delivered to some one other than the original obligor.

89. $\$ 57$.

90. $\$ 55$.

91. $\$ 57$.

92. $\$ 58$.

93. Section 58 merely provides that a "holder" may enjoy the substantive advantages of an earlier holder in due course. The power of the common-law assignee to share them follows from the rule that one may transfer whatever title he himself has.

94. The first quotation is merely the cant phrase for the matter; the second comes from $\$ 58$. 
ends of a fraud-feasor if it were possible for the party to the fraud or an earlier ordinary holder later to occupy a higher position other than in his own right.

The privilege of making such a transfer is to be explained in terms of rewarding the holder in due course who transfers rather than the ordinary holder or assignee who receives. There is nothing unusually commendable in such conduct in receiving. Rather the transferee is granted the substantive advantages already acquired by his transferor because this is necessary in order that the transferor may enjoy to the utmost those advantages granted him as a reward for his admittedly commendable conduct in becoming a holder in due course. Granting the substantive advantages to the lowly ordinary holder or assignee is a means to the end of completely rewarding the exalted holder in due course who, to be properly rewarded, must be allowed not only to enjoy the immunity from personal defenses and claims of ownership himself, but also to sell or give this quality to another to enjoy in his stead, in order to liquidate his investment.

Just as the prospect of being able to make transfer is inducement to becoming an ordinary holder, so is the possibility of conveying the other substantive advantages bait for performing the more commendable conduct of becoming a holder in due course. For that matter, this privilege is nothing beyond that of being able to transfer whatever title one has, which even the ordinary contract law has come to recognize. The law is indifferent as to whether it is rewarding the present holder directly for his own commendable conduct or rewarding the earlier holder who is really entitled to reward for his commercial conduct. This idea of "standing in the shoes" of a holder in due course has its analogy in the provisions of the Statute ${ }^{95}$ which create legal title in the instrument in one who is a transferee without indorsement from an ordinary holder of order paper. Here, too, one may reap the advantages (here procedural) accrued to another without himself performing equally desirable conduct.

\section{The Minimum Commercial Conduct Creating the Procedural Advantages}

The procedural advantages of the ordinary holder are granted only in the case of transactions complying with established ideas of the commercially desirable transaction involving the payment of money. The Statute has numerous provisions which serve to delimit the type of transaction which shall be governed by these peculiar rules. These provisions determine, first as to the initial parties, what are the opera-

95. § 49 . 
tive facts the presence or absence of which shall be necessary for the existence of a negotiable bill or note to which these procedural advantages attach, and second what conduct subsequently creates such advantages both for and against later parties.

The first aspect of these rules is the trend of the law to be not so particular in its demands concerning the operative facts necessary to secure the reward of the procedural advantages as it is with the facts necessary to achieve the substantive advantages of a holder in due course. Thus certain omissions and inconsistencies do not interfere with the instrument's being sufficiently complete and regular to give rise to the procedural advantages, although these shortcomings can render the instrument so incomplete and irregular on its face as, of their own force, to preclude its being held in due course. ${ }^{90}$ This difference, however, would seem to follow from the initial premise of the two levels of advantages resulting from the different levels of commercial desirability in particular transactions. Not only must the surrounding circumstances of the taking by the holder in due course be of a higher nature in order for him to secure the substantive advantages, but the instrument itself must be more perfect in form.

An analogous difference in the relative strictness as to the operative facts necessary to bring into play the rules of bills and notes is seen in the distinction drawn between the commercial conduct necessary to create the procedural advantages for and against the original parties to the instrument at the time of its making, and that necessary to create them for and against additional and later parties, who come into the picture after the issuance of the instrument. In some respects the law is more particular about the internal nature of the operative facts which must appear on the instrument at its inception than it is about comparable transactions entered into later by transferors or acceptors. Thus the face of the instrument must contain words of negotiability ${ }^{97}$ indicating an intention of the original parties that the instrument shall be freely transferable, while the indorsements on the back need not contain such words to carry the quality further. ${ }^{98}$ In fact, subsequent indorsers may specifically restrict such quality by restrictive indorsements. ${ }^{99}$ Thus, also, a condition on the face of the instrument will destroy negotiability ${ }^{100}$ while a conditional indorsement will not; and the Statute sets forth the legal incidents resulting from such an indorsement. ${ }^{101}$ An indorsement may be "qualified" so

96. $\S 52(1)$.

97. $I$ I (4).

98. \$36-end.

99. Section 36 outlines what indorsements are restrictive.

I00. $\$ \S$ I (2), 3, 4-end.

IOI. \$ 39 . 
as to negative liability ${ }^{102}$ while a qualifying provision on the face of the instrument (save as to the drawer) ${ }^{103}$ would defeat negotiability. Acceptances may be ${ }^{104}$ "qualified" by terms which would be fatal to negotiability if found on the face of the instrument. In limited circumstances transfer or subsequent liability can be achieved by writings not a part of the instrument, or by conduct alone, whereas the initial liability (and right to the procedural advantages) must be accomplished by a writing on the instrument itself.

But these differences are consonant with sound commercial policy. It is a sufficient carrying out of the policy of encouraging the circulation of commercial paper if paper when first it gets into circulation comes up to the minimum standard. Subsequent hampering of its circulation by the departures mentioned above does not detract from the fact that the parties are using the approved type of commercial instrument for their transaction. This is the desideratum of the procedural advantages. Qualities which, did they concern the main transaction, would defeat the purpose of the law, may safely be tolerated in incidental dealings, so long as the main transaction is above suspicion of commercial undesirability.

It must be remembered that at this stage we are talking about those operative facts serving to raise the peculiar procedural advantages of the law of bills and notes. As we have seen, other operative facts germane to the common law of contracts are requisite in the establishment of a bill or note as a valid instrument. These others are, however, taken for granted at this point. Certain of the procedural advantages may serve to minimize them or the proof of their existence, and the substantive advantages may make them unnecessary as to holders in due course.

\section{A. The Initial Operative Facts Creating the Procedural Advantages Against and in Favor of the Original Parties}

The necessary initial operative facts fall into two classes: first, facts showing an intention of the original parties to create a transaction which shall be governed by the peculiar rules of the law of bills and notes; and, second, facts indicating with certainty the details of the performance of the transaction, to the end that the transaction shall be internally commercially desirable. ${ }^{105}$ The desire of the parties to subject the transaction to the rules of the law merchant alone will not

102. $\S 38$.

103. $\$ 6 x$.

I04. $\$ \S \mathrm{I} 39, \mathrm{I} 40, \mathrm{I} 4 \mathrm{I}$.

105. Section $I$ states the general requirements as to the form of a negotiable instrument; $\$$ I26 repeats them in defining a bill of exchange; $\$ I 84$ does likewise in defining a note; and $\$ 185$ defines a check as a species of bill, drawn on a bank, and payable on demand. 
suffice unless, further, a transaction is created acceptable to that body of law.

\section{Manifested Intention of the Original Parties to Create a Negotiable Instrument}

The original parties must manifest an intention that the transaction shall be subject to the peculiar rules of the law of bills and notes. ${ }^{100}$ Thus it is that they must both shape the transaction into one of the two forms therein recognized ${ }^{107}$ and, by appropriate words, indicate that they expect the transaction to be freely transferable in the fashion recognized by that body of rules. ${ }^{108}$

The first element is taken care of by the statutory requirement that the instrument must contain either an order or a promise. ${ }^{109}$ These are the respective components of the bill and the note. The bank check, of course, must be recognized as a third definite type of negotiable instrument although, legally speaking, it is a species of bill. The second element, the original parties' expectation of free transferability, is covered by the statutory requirement that the instrument must read either to order or to bearer. ${ }^{110}$ Once the original parties have indicated such an expectation, later parties are held to indicate a similar intention, (unless they specify to the contrary) by their mere dealing with the instrument and are not required expressly to manifest any intention that this quality of transferability shall continue. ${ }^{111}$

\section{Certainty as to the Details of Performance of the Transaction ${ }^{112}$}

Not only must the parties properly indicate an intention that the transaction shall be governed by the rules of the law of bills and notes, but, before these rules will apply, the transaction must possess internally such commercial desirability as to entitle it to the rewards held out by

I06. Section Io provides: "The instrument need not follow the language of this act, but any terms are sufficient which clearly indicate an intention to conform to the requirements hereof."

I07. See $\$ 87$ for an example of how one and the same instrument may be both a bill and a note. Under that, a note payable at a bank is an equivalent to an order on the bank to pay it for the account of the principal debtor. Distinguish, of course, the problem of an ambiguous instrument which may be treated either as a bill or a note under $\$ \S \mathrm{I} 7(5)$ and $\mathrm{x} 30$.

I08. I. e. by "negotiation" as defined in $\$ 30$.

I0g. $\S \S \mathrm{I}(2), \mathrm{I} 26, \mathrm{I} 84$.

IIo. $\S \S \mathrm{I}(4), \mathrm{I} 26, \mathrm{I} 84$. Consider also $\$ \S 8,9$ and 30 .

III. $\S 36$-end. Consider also $\$ 35$ with reference to converting a blank indorsement into a special one.

II2. In Parsons, Notes AND BILls (I865) 30, the author sub-divides the problem of certainty with reference to (I) the payee; (2) the payor; $(3)$ the amount; (4) the time of payment; and, (5) the fact of payment. Concerning this, he says: "It will be seen that the law endeavors to enforce, define, and protect all of these certainties as far as possible. Not, however, in such an exact and technical way as would only embarrass the transaction of business; but substantially, and in a perfectly practical way." 
that body of law. The essential requirement in this respect is certainty as to the details of performance of the transaction.

The Statute has required certainty in five respects: (a) as to the expression of the terms of performance; (b) as to the nature and extent of performance; (c) as to the time of performance; (d) as to the happening of performance; and (e) as to the identity of the performers. These elements of certainty will presently be discussed in that order. The Statute expresses these in terms of legal certainty but, to avoid unfortunate results in situations wherein legal and commercial certainty are not the same thing, has provided numerous (but not sufficient) exceptions which allow of details in transactions which, under the general statement, might be held to violate legal certainty. The courts have also worked out other exceptions. There are still situations where, for lack of statutory exceptions and because the courts have refused to make further ones, certain details of transactions have been held to impair negotiability which do not render the transaction uncertain from a commercial standpoint.

\section{(a) Certainty as to the Expression of the Terms of Performance}

The instrument must be in writing and signed. ${ }^{113}$ Nothing but a writing is capable of that free transferability and concentration of obligation into tangible form which the law of bills and notes demands. Non-written transactions do not create the commercially desirable consequences which are expected to flow from the greater use of bills, notes, and checks. ${ }^{114}$ Further, the writing must be signed by the obligors to be bound. With certain minor exceptions ${ }^{115}$ the procedural advantages of the law merchant cannot be used to enforce liability against any person whose name does not appear on the instrument itself. ${ }^{116}$

If there be a writing and signature, the law is not overly strict about the manner of the writing ${ }^{117}$ nor about the place or technique of the signature, as commercial desirability flows from the fact of writing and signature howsoever and wheresoever. Nor must all the details of the instrument be complete and on the instrument at its inception. The law of bills and notes is very tolerant of blanks in the instrument, so much so that a negotiable instrument will result where one signs a blank piece of paper with the intention that a negotiable instru-

II3. $\$ \S I(I), I 26, I 84$.

II4. Contrast the rules concerning the requirement of writing for the acceptance, $\S \S \mathrm{I} 32$ to 135 , inclusive; and for the indorsement, $\$ 3 I$.

II5. $\$ \$ 49,65,69$, I 37 .

II6. Consider $\$ 23$, dealing with forgery; and $\$ \S 18,19,20$ and 21 , concerning agency.

II7. Section I7 (4) provides that the written provisions shall prevail over the printed in the event of a conflict. Section 17 (I) provides that the words shall prevail over the figures in the event of an inconsistency. 
ment be written above the signature. He will be liable to ordinary holders if the instrument be filled in within a reasonable time in accordance with authority, and to holders in due course regardless. The same follows for less extensive blanks. ${ }^{118}$

While this laxness with respect to blanks may seem to violate commercial desirability in the abstract, yet two considerations suggest that it is desirable to extend the procedural advantages to instruments thus incomplete in their inception. One is the commercial demand for permission thus to issue instruments capable of being shaped to fit unanticipated situations. The other is the realization that when such activity occurs, money transactions have actually been shaped into the molds approved by the commercial law, and the general objective-the greater use of bills, notes, and checks-has actually been attained.

No set phrases are essential to the creation of a bill or a note. ${ }^{119}$ So long as there is an order or a promise, howsoever expressed, it is possible for an otherwise acceptable instrument to reap the reward of the procedural advantages. Finally, the Statute expressly dispenses with the expression of the elements of date, place where drawn or payable, and value given, and provides that the presence of a seal shall not impair negotiability. ${ }^{\mathbf{1 2 0}}$

\section{(b) Certainty as to the Nature and Extent of Performance}

Commercial certainty as to the nature and extent of performance follows when the order or promise is to pay a sum certain in money 121 and to do nothing else. A promise or order to pay an uncertain sum of money, or to do any act other than the paying of money ${ }^{122}$ is thought not to be of the sort desirable of being stimulated by favorable rules of law. The instrument must be for the payment of money, ${ }^{123}$ in a sum certain, ${ }^{124}$ and cannot contain any promise to perform any act other than the payment of money, even though it be only in addition to a subsisting term involving money. The requirement of "money" as such has raised questions concerning the negotiability of instruments payable in non-legal tender money and in money of a foreign country.

II8. $\$ \S \mathrm{I3}$, I4. Contrast the blank indorsement under $\$ \S 34,35$ and 64 .

IIg. \$ Io. Section I7 provides rules for clearing up ambiguities. Section 43 provides that where a payee's or indorsee's name is misspelled the indorsement should be in that name and, as well, in the proper name. Section 63 presumes a signer to be an indorser unless otherwise indicated.

I20. $\S 6$.

12I. $\$ \$$ I (2), I26, 184

122. $\$ 5$.

123. Contrast the similar rule that an acceptance cannot specify for performance other than by the payment of money, $\S \mathrm{I} 32$; although it may be qualified so as to call for payment less than the face sum, \$ I4I (2); or at a particular place, § I4I (3).

124. Section $\S 17$ (I) provides for the situation where there is a discrepancy on the face of the instrument between the expression of the sum in the figures and in the words. 
The Statute has specific provision for the validity of the former, ${ }^{125}$ but the solution of the latter problem is in grave doubt.

So important is this requirement of certainty as to the nature and extent of performance that it is provided that there shall be a discharge of the instrument because of a material alteration if there be any change in the sum payable, ${ }^{126}$ the medium of currency, ${ }^{127}$ or the place of payment; ${ }^{128}$ or the addition of a place of payment if none be specified. ${ }^{129}$

The statutory exceptions ${ }^{130}$ to the prohibition against provisions for the performance of acts in addition to the payment of money merely make it clear that waiver of the benefit of laws favorable to the obligor or the authorization of a confessed judgment or of the sale of collateral securities shall not be construed as promises to perform additional acts. Obviously these provisions do not detract from the commercial desirability of such an instrument. Rather they add to it. ${ }^{131}$ The further exception ${ }^{132}$ validating a provision giving the holder an option to demand something in lieu of the payment of money also clears up a situation not violative of the spirit of the general rule forbidding additional promises. Commercial certainty as to the medium of performance is satisfied if the investor can demand the payment of money. It does not detract from the desirability of the instrument that it contains, in effect, a separate common law agreement whereby the maker agrees to sell some chattel or perform some service for the agreed price of the face amount of the instrument. This exception provides for the commercially desirable transaction of the convertible bond, and thus fosters an approved method of business financing. Numerical certainty in the amount of money involved in performance is also subject to certain exceptions for items which could, otherwise, be strictly construed as being uncertain. Thus the commercially desirable elements of interest, instalment payments, provisions for exchange, and for collection costs may safely be incorporated without defeating the negotiability of the instrument. ${ }^{133}$ These terms also add to, rather than detract from, the commercial desirability of the instrument.

\section{(c) Certainty as to the Time of Performance}

The legal rules which give effect to the law's demand that the instrument shall be certain as to the time of performance possess less

I25. $\$ 6(5)$.

I26. \$ I25 (2).

127. \$ I25 (5).

128. \$125 (3).

129. \$ I25-end.

I30. $\$ 5$, parts I, 2 and 3 .

I3r. It would be peculiar if the express provision for advantages to the holder in enforcing the obligation should be held to deprive him of those the law confers upon him for becoming a holder.

I32. $\$ 5(4)$.

I33. $\$ 2$; see also $\S x_{7}(2)$. 
rationality than those just discussed. The basic rule is that the instrument must be payable on demand or at a fixed or determinable future time. ${ }^{134}$ Thus it is not always required that the time of performance be certain. Demand paper, ${ }^{135}$ which is expressly authorized, is the most uncertain type of paper, leaving the payor in the dark as to when he may be called upon to pay. In view of the general policy of favoring the investor at the expense of the debtor, it would seem that commercial desirability with respect to certainty in the time of performance would be satisfied if, in any type of paper, the investor could be certain just how long his investment would last and could be free from unexpected tender by the payor which would deprive him of his interest and right to court costs incident to suit. But, save in the case of paper stated outright to be demand paper, ${ }^{136}$ it is the policy of the law that there must be as much certainty for the debtor as for the creditor and that an instrument which is uncertain as to time other than by being demand paper is non-negotiable.

An apparent exception to this is "anticipation" paper, by which the debtor at his option may make advance payment before a definite due date. ${ }^{137}$ This type of transaction is considered to be commercially desirable because it enables the investor to know the ultimate date on which he can collect, and the debtor to know the ultimate date on which he must pay. The only departure from certainty lies in the fact that the investor may have either to reinvest his money or to lose the interest for the balance of the period after the debtor has exercised his option to anticipate.

Paper payable on an uncertain contingency is obviously uncertain both as to the time of performance and the occurrence of performance and, for that reason, is non-negotiable. ${ }^{138}$ The Statute relaxes this rule slightly by allowing time paper to be made payable on the happening of an event which is bound to happen, even though the time of occurrence is uncertain. ${ }^{130}$ This must be treated as a frank statutory departure from the principle of commercial certainty as to time of performance, for the paper here in question is commercially undesirable. The statutory exception for instalment payments and for accelerability of the due date upon default in any one instalment ${ }^{140}$ is a commercially desirable term which might be held to violate the general legal rule for certainty in time of performance.

I34. $\$ \$$ I ( 3$), I 26, I 84 ; \$ 25$ mentions the distinction.

I35. See $\$ 53$ (when demand paper is overdue for holding in due course); $\$ 7 I$ (when presentment of demand paper must be made).

I36. $\$ \$ 4,7$.

I37. $\$ 4(2)$.

I38. \$4-end.

I39. $\$ 4$ (3).

I40. $\$ \S 2(2), 2(3)$. 
Perhaps the most paradoxical aspect of the law of bills and notes in this respect is the attitude of the law toward acceleration clauses generally. While the Statute expressly recognizes the negotiability of demand paper, and of time paper which is either payable at a specified day or at the expiration of a specified period after date or sight, ${ }^{141}$ the attitude of the courts thereunder has been that paper is rendered nonnegotiable because of uncertainty in time if it be made payable at a fixed or determinable day, or sooner, at the unbridled option of the holder. In substance, of course, such an instrument is nothing more than demand paper with an ultimate fixed due date. But apparently the courts have adhered to the doctrine that in order that demand paper be negotiable the instrument must state the "demand" quality outright and not indirectly by granting permission to accelerate time paper. On the other hand, the courts have been prone to uphold the negotiability of paper accelerable by the holder on the happening of a so-called "objective event". While at first this type of paper would seem more uncertain than that type which the law upholds under another name"demand"-still, there seems to be a good analogy here to the rule applicable where there is a contingency mentioned which is certain of occurrence.

The strongest argument against holding that acceleration clauses defeat negotiability is that the rule as now applied leads to quibbling about what is an objective event and what is the whim or caprice of the holder.

A further detail of the element of certainty in time is that concerning the dating of the instrument. The law of bills and notes is peculiarly indifferent to the dating, probably because of a recognition either of the indifference in commercial practice to the accuracy or presence of a date, or of the custom of writing and dating the instrument on one day and making actual delivery on another. The Statute, in this vein, provides that it is not necessary that the instrument shall be dated, ${ }^{142}$ and that if there be no date the instrument shall count as of the actual date of its issue ${ }^{143}$ that where the presence of the initial date or date of acceptance is essential to fix the exact date of maturity of an instrument running for a certain period from issue or presentment for acceptance the holder may cure the omission by the insertion of the true date; ${ }^{144}$ that a date actually inserted at the time of any operative signature shall be presumed to be the true date; ${ }^{145}$ and that

I4I. $\$ 4(x)$.

I42. $\$ 6(\mathrm{I})$.

143. $\ 17$ (3).

I44. $\$$ I3. Contrast $\S$ I 4 I (4) (acceptance may be qualified as to time).

I45. § II. 
ante-dating or post-dating shall not affect the validity of the instrument unless done for an illegal or fraudulent purpose. ${ }^{146}$

The importance of certainty in time is to be seen in the rule that alterations of the instrument with respect to the time of performance are material, ${ }^{147}$ and in the rules aiding in the determination of the exact due date in doubtful situations. ${ }^{148}$

\section{(d) Certainty as to the Happening of Performance}

No conditions may be attached to the requisite order or promise. ${ }^{149}$ Paper which on its face indicates an uncertainty as to the happening of the performance of the obligation does not have that commercial desirability which calls into play the peculiar rules under discussion. ${ }^{150}$ The determination of what constitutes an objectionable condition on the face of the instrument has given rise to no little quibbling. The problem is connected with that of certainty in time. An instrument payable on the happening of a contingency is not negotiable ${ }^{151}$ and the happening of the contingency does not cure it. There is uncertainty then both as to the time of performance and the happening thereof.

Two types of term typically found in certain kinds of instruments raise questions of this obstacle to negotiability. One is the indication by words of the fund or account to be charged, and the other is the notation on the instrument of the underlying transaction for the satisfaction of which the instrument is issued. For the former the Statute provides a complementary set of standards. If payment is to be made "out of a particular fund", negotiability is destroyed, 152 but if the term is merely "an indication of a particular fund out of which reimbursement is to be made; or a particular account to be debited with the amount", ${ }^{153}$ negotiability is not impaired.

In the case of the notation of the transaction in which the instrument is used, the Statute has more clearly settled the issue in favor of negotiability. A "statement of the transaction which gives rise to the instrument" 154 is specified not to impair negotiability. In order that the instrument be held non-negotiable because of the presence of a condition, there must be contained in the instrument a statement specifi-

I46. § I2.

147. Section I25 (I) (change of date); § I25 (3) (change of time of payment).

148. Section 85 (days of grace abolished, provisions for instruments falling due on Saturdays, Sundays, and holidays); $\$ 86$ (how running of time computed).

149. $\$ \$$ I (2), I26, I84.

I50. But indorsements may be conditional, §39; as may acceptances, § I4I.

I5I. \$4-end.

I52. \$ 3-end.

I53. $\$ 3(1)$.

154. $\$ 3(2)$. Section $6(2)$ makes it clear that it is not necessary to state the value for which the instrument is given, although $\$ 6$-end provides that any local statutes requiring the nature of the consideration to be stated in the instrument shall remain in force. 
cally conditioning the performance ${ }^{155}$ of the promise or order on the carrying out of the underlying transaction.

\section{(e) Certainty as to the Identity of the Performers ${ }^{156}$}

The parties who are expected to perform must be named on the instrument by the intentional affixing of their signatures or names. ${ }^{157}$ In the absence of such naming, no liability under the law of bills and notes can accrue. Where such parties, viz., a maker on a note and a drawer and drawee on a bill, are lacking, there can be no negotiable instrument, although the law is lax in this respect and will permit a defective bill to be treated as a note where there are not enough parties for the former but there are for the latter. ${ }^{158}$ If signatures do appear on an instrument, liability is apparently intended, and that of the sort indicated by the location of the signature, or the juxtaposition of appropriate words, or by indicative words appended to the signature. Where, for lack of any of these circumstances, it is ambiguous as to the capacity intended by the signer, whether maker, drawer, acceptor or indorser, the law solves the dilemma by an arbitrary presumption ${ }^{159}$ that the party intended to be an indorser. In the case of the bill of exchange, the law further requires, in order that there be a valid and complete bill, that the drawee be named or otherwise indicated with reasonable certainty in the original bill, ${ }^{160}$ and forbids the addressing of a bill to two or more drawees in the alternative or in succession, although the instrument may be addressed to two or more jointly. ${ }^{161}$

From the angle of certainty in the parties who are to receive performance the law is not so particular. It is not required that the beneficiaries of performance be denoted with exactness in the origin of the bill or note. But this is an aspect of the tendency of the law to favor the investor rather than the debtor. It is far more important that the investor know who his debtor is than that the debtor should know the identity of his creditor. For an investor to take paper in ignorance of the identity of his debtor would be to engage in a commercially undesirable transaction and one lacking the superior qualities essential to the extension of the procedural advantages. But there is no analogous undesirability in the debtor's agreeing to be liable to one who is in the beginning unknown to him. So it is that the paper may be

I55. One of the most difficult problems arising under the Statute is that of the negotiability of mortgage notes. Consider $\S 5(\mathrm{I})$, making it clear that it does not defeat negotiability to authorize the sale of collateral security.

I56. Contrast $\$ 125$ (4), making it a material alteration to change the number or relations of the parties.

I57. $\$$ I (I), I8, I26, I84.

I58. § I7 (5).

I59. §§ I7 $(6), 63,64$.

I60. \& I (5).

I6r. \& 128 . 
and, in fact, must be ${ }^{162}$ made payable to either an unknown and unindicated bearer, ${ }^{163}$ or to the order of a specified person or persons ${ }^{164}$ who may, ${ }^{105}$ in turn, order its payment either to another originally unknown person, or to the larger group of unknown "bearers". The net result is that practically any denoting of the payee by any name whatsoever results in the paper being either bearer or order paper. If a blank space be left for the payee's name, this may be filled in in any approved fashion, ${ }^{106}$ and the only situation in which paper is defective for lack of some indication of the original payee is where there is neither blank space nor some name, artificial or natural, in the normal place for the payee's name. Further, even where the intention is temporarily to limit the beneficiary of performance to one person, a misdescription of that person, is, by the Statute, made unimportant. ${ }^{187}$ The paper may, in fact, be made payable in the first instance to the maker or drawer himself, ${ }^{168}$ or to the drawee, ${ }^{169}$ in which event it acquires completeness when indorsed. ${ }^{170}$ When, in a bill, drawer and drawee are the same, the holder may elect to regard it as a bill or a note. ${ }^{171}$

B. The Subsequent Operative Facts Creating the Procedural Advantages Against Additional Parties-Liability by Acceptance, Indorsement, or Transfer Without Indorsement 172

Now we shall treat of those additional operative facts which may be, but need not be, on the instrument in order that there be created the procedural advantages as against persons other than the maker or the drawer. These consist in acceptance or certification by the drawee of a bill or check and in indorsement or other transfer by anyone of a bill, a check, or a note. The requirement common to both is the same as where it is a question of the liability of the drawer or maker, viz., that no person is subject to be proceeded against with the aid of the procedural advantages, unless his signature is obtained ${ }^{173}$ although, of course, the signature may be appended by an agent acting with au-

I62. \$ I (4).

I63. Section 9 determines when an instrument is payable to bearer.

I64. Section 8 determines when an instrument is payable to order; $\$ 41$ treats of the problem of who must indorse when the instrument is made payable to or is indorsed to two or more persons.

I65. § 34.

I66. \$ I4.

16\%. $\$ 43$. Contrast $\$ 42$.

I68. $\$ 8(2)$.

169. $\$ 8$ (3).

170. This is expressly provided as to notes in $\S 184$. There is no equivalent provision as to checks in $\$ 126$, although the two sections are otherwise parallel.

I7T. $\$ 130$.

I72. Consider the sections of the Statute on acceptance and payment for honor, not otherwise treated herein, $\$ \$ 16 \mathrm{I}$ to 177 , inclusive.

173. $\S \S 18,23,132$. 
thority, ${ }^{174}$ or liability may be imposed without a signature as a penalty for commercially undesirable conduct, ${ }^{\mathbf{1 7 5}}$ or by operation of law for sound reasons of policy as in the case of the warranty liability.

By acceptance the drawee assents to the order of the drawer ${ }^{178}$ and thereby adds his liability to the instrument, which is then capable of being enforced against him through the procedural advantages which accrue to an ordinary holder. The certification of a check is the equivalent of an acceptance. ${ }^{177}$ No doubt because of the usual informality of commercial practice in this respect, the Statute is indifferent about the time of acceptance and the then completeness of the instrument. It recognizes acceptance before the drawer has signed, or when the bill is overdue, or incomplete, or after a previous refusal of acceptance or payment. ${ }^{178}$ None of these factors is thought to detract from the commercial desirability of the transaction.

On the other hand, commercial desirability seems to demand strictness in the matter of who may accept. If a would-be bill lacks a sufficiently well indicated drawee, ${ }^{179}$ it is no bill in the first place, and, further, if one attempts to accept a bill addressed either to no one, or to another, the transaction is too informal to raise the procedural advantages incident to the properly created liability of an acceptor. The acceptance must be by the named drawee, and if one attempts to "accept" a bill addressed to another, or to no one, while he may acquire the implied liability of the maker of a note, or of the indorser of an instrument, ${ }^{180}$ he does not become the acceptor of a bill subject to the procedural advantages incident thereto. The transaction then lacks the commercial desirability which can create that status.

Save in the case of the one who "constructively" accepts by his misconduct with the bill, no one can be held liable as an acceptor-even if he be the named drawee-who has not affixed his signature either to the bill as such, or, within the narrow exceptions therefor, to another piece of paper. The rule that a drawee cannot be sued until he either accepts or certifies is also expressed as the rule that a check ${ }^{181}$ or a bill ${ }^{182}$ does not act as an assignment. This rule, based as it is on the common law's rejection of a "split assignment", has its justification in considerations of commercial expediency. Bills, and particularly checks, are rarely for the exact amount which the drawee owes

I74. § I9; see also $\$ \S 20,21$.

I75. $\$ \$ 49,137$.

I76. \$ 132 .

I77. $\$ 187$.

I78. $\$ \mathrm{r} 38$. Contrast $\S 64$ (liability of irregular indorser).

I79. $\S$ I $(5)$.

I80. $\$ \$ 17(6), 63$.

I8I. $\$ 189$.

182. § 127 . 
the drawer or has agreed to stand ready to advance. To allow the holder to acquire a right of action in all cases, possibly on an analogy to the third party beneficiary, merely by observing the routine of common-law assignments, might subject the drawee to the unanticipated intolerable inconvenience of frequent suits. It is better to leave the question of whether the drawee should have honored the order to be settled between drawer and drawee than to let it be litigated by a stranger to their dealings. The Statute does not entirely forbid the bill or check to be treated as an assignment, but rather stipulates that they of their own force shall not attain that status. Extrinsic considerations may show that it was the intention of the parties that there be an assignment which, if proven, will be given that force. ${ }^{183}$

The "constructive" acceptance is one instance of where one can be held liable as an acceptor without signing his name. As a penalty for the commercial misconduct of the drawee's destroying the bill or refusing to return it after it has been left with him for the purpose of allowing him to make up his mind whether to accept, the law imposes on him the same liability as if he had accepted. ${ }^{184}$

In accordance with the policy of requiring certainty in the expression of the terms of performance, the normal requirement is that the acceptance be written, and preferably on the instrument rather than somewhere else. ${ }^{185}$ But there are two exceptions to this latter rule which recognize typical commercially desirable transactions wherein it is inexpedient that the acceptance be written on the instrument. The one is the provision for the written promise to accept, made in advance of the drawing of the bill, ${ }^{186}$ and the other is the provision for an actual acceptance on another piece of paper after the utterance of the bill. ${ }^{187}$ The former provides for the "letter of credit" situation and the latter for the situation wherein the drawer finds it necessary to raise funds quickly in a place distant from that of the drawee, who may accept by telegram.

In accordance with the policy of certainty in the medium of performance the acceptance must be for the payment of money and nothing else. ${ }^{188}$ But it is not required that the acceptance be in exact accord

I83. Although, of course, the fact that the extrinsic considerations may rest entirely on the conduct of the drawer would seem to indicate that the convenience of the drawee is not the rationale of the rule. Suggestions have been made that the fact that the check or bill is for the exact balance on deposit with the drawee shows an intention to make an assignment. This would not depart from the idea of the convenience of the drawee because, then, there is but one item to be dealt with and no danger of a "split assignment." The writer is informed that some banks automatically close out a checking account when a check for the exact balance is honored.

I84. $\$ \S 136$, I37.

I85. $§ \mathrm{I}_{2}, \mathrm{I} 33$.

I86. § 135 .

I87. $\$ 134$.

I88. § 132 . 
with the tenor of the order addressed to the drawee. It is felt that commercial desirability should permit the drawee to depart from the limits of the order addressed by the drawer so long as his contract is itself commercially certain. This is in accordance with the policy of the law of bills and notes to be less strict with the incidental transaction involving the instrument than with the original tenor thereof. Thus an acceptance -may be qualified ${ }^{180}$ although the holder's taking of the qualified acceptance has its incidental effect on the liability of secondary parties, later to be discussed. ${ }^{190}$ The drawee may, if the holder be willing, accept on condition generally, or on condition that he will pay part only of the amount, or at a particular place or time. Further, less than all the drawees may accept. ${ }^{101}$ These departures in themselves contain no commercially undesirable elements and the only suspicion attached to the desirability of the transaction is that there is a departure from the original tenor of the instrument.

The other type of operative facts which have the effect of adding new liability to an instrument which is otherwise already complete is that involved where an instrument is indorsed or transferred. While there are various classifications of indorsers, yet, from the standpoint of the relation of the indorser to the instrument at the time of indorsing, it may be said that an unqualified indorsement may be one of three kinds, in the event of anyone of which the indorser acquires the inchoate secondary liability later to be discussed. The indorser may be the socalled anomalous indorser (probably for accommodation) who was not, when he indorsed, the holder of the instrument; ${ }^{192}$ he may be one who was at the time the holder of paper which, because it was then bearer paper, did not require his signature for effective transfer, and who accomplished only liability (and a record) by his signing; ${ }^{193}$ and finally, he may be one who was the holder of paper which, because it was then payable to his order, required his signature for the accomplishment of complete transfer, the signing then accomplishing both complete transfer and liability. ${ }^{194}$ In any event, the operative facts are exactly the same, to wit, the signature of the alleged indorser accompanied by the presumed ${ }^{195}$ common-law requirement of delivery-which latter by itself accomplishes complete transfer and some liability ${ }^{196}$ in the case of bearer paper. Any unexplained signature on the paper is presumed

I89. $\$$ ז39.

I90. \& I 42 .

IgI. $\$$ I $40,14 I$.

I92. Section 64 applies to such an indorser "before delivery". See also $§ 63$.

I93. $\$ 67$. Consider $\S 40$ to the effect that one indorsing specially on bearer paper is liable only to those who make title through his indorsement.

194. $\$ 66$.

I95. \$ 26.

I96. \$ 65 . 
to be that of an indorser. ${ }^{197}$ This provision provides well for the first two classes of indorser, as outlined above.

Presumptions aid in solving the question of the order of liability of numerous indorsers who may appear on the back of the instrument ${ }^{198}$ and as well help solve questions of the time and place of the indorsement. ${ }^{199}$ But the policy of commercial desirability, in both the liability and the transfer aspects of indorsement, is satisfied by nothing more than the signature of the party sought to be bound or whose signature is essential to transfer. ${ }^{200}$ Thus is recognized the commercial custom of relying on the signature alone for these purposes. The indorsement not only serves as a vehicle of liability and transfer but also serves as a receipt signed by the indorser and as a record of the travels of the instrument. That the indorsement can be demanded for these latter commercially desirable purposes, or that one whose signature is essential for transfer may append his name without incurring full liability ${ }^{201}$ (whereby squeamish holders will be encouraged to transfer), provision is made for the so-called qualified indorsement-_"without recourse"-which does, if needed, accomplish transfer and does not defeat negotiability or the possibility of a holding in due course but precludes the full liability aspect of indorsement. ${ }^{202}$ Somewhat the same result is incidentally accomplished by the restrictive and conditional indorsements. ${ }^{203}$ There is no objection to the writing of special guaranties by additional parties on bills and notes, but inasmuch as the signature thereto alone accomplishes as much as the typical guaranty, it is difficult to conceive of such common law obligations on negotiable instruments presenting problems. Suffice it to say again that once the procedural advantages have come into being as to the original parties the same advantages are available against any others who for whatever purpose, necessary or otherwise, have intentionally affixed their names to the instrument.

The normal liability which flows from the fact of indorsement is the so-called "secondary" liability (akin to that of the drawer), which is a liability to pay the face of the instrument upon the conditions of presentment, demand and notice. In addition, and without the conditions, there is the "warranty" liability of the unqualified indorser, 204 whereby, by operation of law, he guarantees that the instrument is valid

197. $\$ \S I 7(6), 63$.

198. $\$ 68$.

I99. $\$ \$ 45,46$.

200. $\$ 3 \mathrm{r}$.

20I. See $\$ \S 20,44$ on indorsement in a representative capacity so as to negative personal liability.

202. $\S 38$.

203. $\$ \$ 36,37,39$.

204. § 66 . 
and subsisting, that it is genuine, that he has good title, and that prior parties had contractual capacity. The qualified indorser and the transferor without indorsement, neither of whom incurs the "secondary" liability, make warranties not quite so extensive ${ }^{205}$ (in that they warrant that they have no knowledge of any fact to impair the instrument rather than that it is valid and subsisting) although, in the case of the mere transferor, the warranty runs only in favor of the immediate transferee.

\section{The Subsequent Operative Facts Creating the Procedural Advan tages in Favor of Additional Parties-Transfer by Indorsement, Delivery, or Assignment ${ }^{206}$}

Now the further question arises: who is entitled to exercise the procedural advantages against those persons who have committed the operative facts essential to make them liable? Obviously as to the original beneficiary of the transaction, the payee of order paper, or the one to whom bearer paper is actually first issued, no question is presented. The same operative facts which render liable the parties whose names are either on the instrument or subsequently procured, settle it that the payee or first bearer shall be entitled to the advantages awarded the ordinary holder. The question now is: what further operative facts are essential in order that others than the original payee or bearer may become completely entitled to these procedural advantages in enforcing the liabilities of maker, drawer, acceptor and indorser? The answer is: the further delivery of the paper, if it be bearer paper, or the indorsement and delivery of it if it be order paper. These further transactions of change of possession alone in the case of bearer paper and signature plus change of possession in the case of order paper are in themselves sufficiently commercially desirable to carry forward the procedural advantages of the ordinary holder and to cause them to be extended to the recipient of possession in the one case or possession plus signature in the other. ${ }^{207}$

What conduct is essential to the most complete transfer of the procedural advantages to new beneficiaries depends on whether the paper is at that moment bearer paper or order paper. If then running to bearer, nothing more than intentional delivery is essential and, as we shall see, one of the procedural advantages is that it is presumed that this has validly happened whenever the instrument is out of the possession of one whose signature appears thereon. If, on the other hand, at the moment in question, the instrument is then payable to

205. $\$ \$ 65,69$.

206. By assignment is meant a contract of transfer of an absent instrument.

207. \$§ $30,3 \mathrm{I}, 34,35$. 
order, either to the order of the initial payee, ${ }^{208}$ or, because this quality has been carried forward by a special indorsement to someone else, ${ }^{209}$ then the signature of the payee or special indorsee ${ }^{210}$ is also essential to a completely valid transfer of the procedural advantages. ${ }^{211}$ Complicated questions arise as to whether paper is, at a given moment, payable to order or to bearer. The Statute has explicit provisions for determining from the manner of denoting the payee, whether paper is payable in the first instance to order or to bearer. ${ }^{212}$ The original parties are permitted to indicate whether the beneficiary of the transaction shall be a specified person ${ }^{213}$ or another to be designated by him on the one hand or any person on the other. If the former, that specified person can either designate another one specifically to receive the benefit of the transaction, viz., by a special indorsement (which need not itself contain words of negotiability) or he can, by indorsing in blank, indicate an intention that the paper shall henceforth be payable to bearer and that no further signature shall be essential to a complete transfer. ${ }^{214}$ It seems clear that paper originally payable to bearer continues such despite a later special indorsement, ${ }^{215}$ but the status of paper originally to order, made into bearer paper by a blank indorsement, and still later indorsed specially does not seem so clear. ${ }^{216}$ In any event, either a restrictive indorsement, or the permitted writing of a special indorsement over a blank indorsement ${ }^{217}$ may make more signatures essential to a completely valid transfer of the procedural advantages than otherwise.

There is no requirement of commercial desirability as to the minimum conduct necessary for effectual transfer. As far as the law is concerned, the parties at any stage are permitted to make it possible for the instrument later to be transferred either by the simple act of delivery or by indorsement. ${ }^{218}$ The legal detail of the Statute concerns itself with working out specific rules to give effect to variously manifested intentions in this respect. However, in situations where the indorsement of a given party is beyond doubt essential to a completely valid transfer, the law is concerned with the detail of that transaction, much in the same way as it is concerned with the internal nature of

208. Section 184 provides for a note payable to the order of the maker.

209. See $\$ \$ 34,40,43$.

2ro. Consider $\$ 23$ (forgery is an absolute defense). of them.

2II. See $\$ 33$ outlining the kinds of indorsement, and $\$ \S 34$ to 39 , inclusive, treating

212. $\$ \$ 8,9$.

213. See $\$ \$ 8(4), 8(5), 4$ I (where two or more are named); $\$ 42$ (payable to one as "Cashier", etc.).

214. $\S \S 3 \mathrm{r}, 34 ;$ cf. $\S 35$.

215. \$ 40 .

216. $\$ \$ 9(5), 40,48$.

217. $\$ 35$.

2I8. $\S$ I (4). 
the major transaction itself. Thus, under the policy of demanding certainty in the expression of the terms of the transaction, a necessary indorsement must be on the instrument itself or on an attached paper, and must be manifested by the signature of the necessary indorser. ${ }^{219}$ Likewise, in accordance with the common law policy against split assignments and the commercial policy against allowing the obligor to be harassed by competing obligees, it is forbidden to make an indorsement of but part of the instrument, although it is permitted to do that which neither policy forbids, to indorse the entire balance of an instrument which has been partly paid off. ${ }^{220}$

Not only may one whose signature is essential to complete transfer elect whether to continue the paper as order paper, or, by a blank indorsement, convert it into bearer paper, but he may also indorse in a peculiar or unusual manner so as to limit the interest obtainable by his indorsee and subsequent holders. ${ }^{221}$ Thus the conditional indorsement is sanctioned. This enables the indorser to stipulate that both the liability and transfer aspects of the indorsement shall be conditional upon the happening of a certain event. ${ }^{222}$ The Statute makes this consonant with commercial desirability by privileging the obligor to pay to the conditional indorsee or one holding under him regardless of the happening of the condition. The result is that the matter of the happening of the condition becomes a purely personal one between the conditional indorser and his indorsee and those privy to the latter. By means of the restrictive indorsement ${ }^{223}$ the indorser can either terminate the possibility of a bona fide holder, retain for himself the beneficial interest in the instrument, or indorse to one in trust for another. These devices are provided in recognition of undoubted commercial demands for legal means whereby the instrument can be entrusted to another without the risk of embezzlement or other misuse. 224

But it is not always necessary that the mode of transfer be of a sort encouraged by the law merchant in order for additional parties to enjoy the procedural advantages. A much debated section of the Statute ${ }^{225}$ provides that the transferee for value of order paper from the holder thereof without indorsement shall have the legal title to the instrument and, in addition, the right to have the indorsement (upon. suit in equity). This, in effect, allows one who is not even an ordinary holder to avail himself of the procedural advantages by standing in the shoes of such a holder who was, himself, entitled to those advan-

224. Cf. \$4I (where payable to two or more). 225. § 49 . 
tages. This matter can well be analogized to the earlier discussed capacity of an ordinary holder, or even an assignee, to claim under a holder in due course and, through him, be entitled to the substantive advantages.

While the permitting of a transferee of order paper without indorsement to enjoy the procedural advantages might seem a departure from the normal policy of encouraging approved types of commercial dealing, yet, as we have seen in the case of the capacity to claim under a holder in due course, it is nothing more than a manifestation of the common-law rule that one can transfer what one already has. In truth, such a transferee without indorsement does not have as many procedural advantages as the holder from whom he takes informally, for he must prove the transfer to him by common-law rules, rather than with the aid of the procedural advantages which would surround the proof of transfer to him had he taken by indorsement. He acquires, under the statutory provision, the benefit of the procedural advantages as to events prior to the transfer to him. He would, no doubt, acquire the same status under modern assignment statutes without the benefit of the particular provision in the Statute on the matter. What he fails to acquire is the present possibility of holding in due course, for only a holder (which he is not) may have that status. The position of a person owning under these circumstances is also akin to that of the one claiming as a restrictive indorsee. ${ }^{228}$ Subject, of course, to the purposes of the restriction, the restrictive indorsee acquires the rights to receive payment of the instrument, to bring any action his indorser could bring, and to transfer these rights if the form of the indorsement permits. ${ }^{227}$ In effect this creates in subsequent transferees almost all of the procedural advantages, although, as for the person claiming under Section 49, the transfers must be proved by common-law rules and there is no possibility of a holding in due course.

[To be concluded.]

226. For a discussion of the status of restrictive indorsees, see Smith, supra note 7. 227. $\$ \S 36,37,47$. 